\title{
FACULTY CAREERS: Maturation, Demographic, and Historical Effects
}

\author{
Janet $H$. Lawrence and Robert T. Blackburn
}

\begin{abstract}
Sixty-five University of Michigan arts and science faculty members were interviewed on a number of matters related to their careers. Roughly one-third joined the faculty as assistant professors in each of the three years, 1960, 1965, of 1970. Vitae were used to obtain scholarly productivity measures. The data were analyzed with regard to productivity, promotion rate, and perceptions and values of faculty with respect to the weight that research, teaching, and service are and should be given in promotion decis sions. The various outcomes were then examined from the perspectives of maturation (aging), demographic (cohort), and historical effects. The conclusion is that different perspectives are needed to explain different phenomena. Cohort effects, sometimes modified by historical events, were more effective and called upon more often than were explanations relating to age.
\end{abstract}

As an area of inquiry, faculty development has come to a critical juncture in its evolution. During the last decade, researchers have applied diverse theoretical paradigms to the study of academic careers, and the result has been some interesting but often contradictory explanations for the same phenomena.

The purpose of this exploratory investigation was to distinguish among characteristics of professors that derive from different sources. Specifically, the researchers selected generalizations about changes in faculty behavior, values, and perceptions and sought to identify those that were attributable primarily to psycho-social aging processes (aging effects); changes in the composition of age strata (demographic cohort effects); and key social events (historical effects).

\section{THEORETICAL FRAMEWORK}

Within the literature, one commonly finds study results that show an inJanet H. Lawrence and Robert T. Blackburn, University of Michigan.

Research in Higher Education (C) 1985 Agathon Press, Inc. Vol. 22, No. 2 
verse linear relationship between scholarly productivity (publication rate) and chronological age (Fulton and Trow, 1974; Blackburn, Behymer, and Hall, 1978; Long, 1978). At least one researcher has found a saddle-shaped curve indicating that for many faculty members productivity peaks in their thirties, drops off, and then peaks again in their fifties (Pelz and Andrews 1976; Bayer and Dutton, 1977).

There is also evidence to support the idea that values and perceptions of faculty subgroups may differ. Although they do not necessarily devote more time to teaching, older professors tend to identify more with their roles as teachers and as members of a particular institution, whereas younger faculty members tend to view themselves as disciplinary scholars (Baldwin and Blackburn, 1981; Klapper, 1969).

In addition, researchers have found that since the mid-1970s, Ph.D. output has far exceeded the number of available academic positions (Cartter, 1976). Opinion surveys suggest that within graduate universities especially, but also within smaller undergraduate schools, academicians believe that the emphasis on scholarship has increased and that assistant professors must show great promise as scholars and be at least adequate teachers.

Three theoretical frameworks have been invoked to explain the phenomena. Aging, cohort, and historical conceptual schemes have been used. Each is discussed in turn.

\section{Aging Effects}

Some authors have used developmental models to account for age group differences in productivity, perceptions, and values (Baldwin and Blackburn, 1981; Sanford, 1971; Hodgkinson, 1974). Little or no longitudinal data are available showing that changes are age-related and recur across generations of professors. The consistency of the findings from cross-sectional studies, however, has led writers to infer that certain attributes are the result of ongoing psychosocial aging processes.

Variations in career patterns are assumed to result from professors' selfexaminations that occur predictably during transition periods. The onset of the decline in scholarly productivity is, for example, attributed to the resolution of developmental tasks that predominate during the age 40 transition. Hodgkinson (1974) and Baldwin and Blackburn (1981) believe that for many professors, this is a time when they realize that they may never become the great disciplinary scholar that was their ideal early in their careers. Hence, they begin to build life structures around new identities in which research is less central.

Changes in the values that underlie these role configurations are also thought to be manifestations of the aging process. The data suggest that pro- 
fessors in their mid-to-late thirties (a time period roughly corresponding to post-tenure) experience a sense of overload and are forced to choose among multiple role demands (Hodgkinson, 1974; Baldwin and Blackburn, 1981). Braskamp, Fowler, and Ony (1982) believe that the deemphasis of research reflects a general desire for a balanced set of roles. Sanford (1971) asserts that the greater valuation of teaching and service emerge as professors deal with the task of developing genuine relationships with others.

Finally, authors have noted that older professors tend to report a greater affinity for their institution as well as a greater understanding of how it operates (Baldwin and Blackburn, 1981). Such study results can be linked inferentially to the developmental tasks that predominate among older adults (Kimmel, 1974). It is important for professors in the later phases of their careers to believe that their lives have integrity - that they have helped make their colleges and universities what they are and that their years of service have mattered.

\section{Cohort Effects}

A second group of authors has investigated the impact of socialization to the discipline/profession and to the professorial role on faculty productivity and values (Clark and Corcoran, 1982; Parsons and Platt, 1973; Trow, 1977). While they acknowledge the existence of age group differences, these investigators question the likelihood that variations are the result of age-linked predispositions. Instead, researchers like Pfeffer (1983) and Pfeffer, Leong, and Strehl (1976) argue that differences can be accounted for by cohort flow and the demographic composition of a faculty at a particular point in time.

A key assumption that underlies the cohort explanation for differences in scholarly productivity is that people are more malleable during certain periods of their lives and that socialization experiences at these times have lasting effects on their careers (Pfeffer, 1983). Hence, professors who complete their graduate work and achieve tenure during the same historical era (demographic cohort) are enculturated with a particular set of values that remain constant over time. ${ }^{1}$ What appear to be age-related differences in productivity or values are actually cohort effects. As the composition of age strata within higher education changes because of cohort flow, the characteristics of the age groups will be altered.

Shifts in professional activities that occur within cohorts are thought to result from changes in the demographic composition of the faculty (McCain, O'Reilly, and Pfeffer, 1982). For example, staff turnover can create important gaps in the curriculum and result in increased teaching loads for those who remain as they have to cover areas in which they are not experts. Shifts in the composition of the administration can lead to new institutional priori- 
ties that, in turn, lead to changes in activities.

The growing affinity with a particular institution may also be a cohort effect. McCain et al. (1982) have found that as the average age and length of service of a faculty increase, so does the degree of consensus about priorities and the sense of influence in decision making. The professors have had greater opportunity to develop a similar outlook. The greater institutional identity among senior faculty members may, therefore, be due to the fact that they and administrators are likely to be from the same demographic cohorts and to be integrated into the same communication networks. Also, noncontinuing faculty were more likely to have been removed from the dominant group and, hence, will leave a more cohesive cohort.

\section{Historical Effects}

The pervasive impact of critical events has been elaborated upon by higher education commentators who attribute shifts in faculty performance and values to changes within the larger society. Key distinctions between cohort and historical effects have been drawn by previous researchers (Cutler and Bengtson, 1974). Cohort effects occur over time and may result in greater differences or similarities among subgroups in an organization. Historical effects, on the other hand, manifest themselves soon after a precipitating event, and the pattern in the data is the same across age groups. It is assumed that persons' responses to the event will be in the same direction, though perhaps not of the same magnitude, and the trend will persist until social conditions cause changes in behavior.

Light (1974) argues that changes in professorial role expectations are influenced by priorities within disciplinary and professional associations and pressure generated by government agencies and special interest groups. Parsons and Platt (1973) identify critical social movements which they believe accounted for the universal student and faculty discontent in the 1960s and the resultant changes in values and behavior. In both instances, the authors assert that variations in performance and norms tended to follow a similar pattern across a faculty as members responded in like fashion to the same social forces. By logical extension, then, it would be assumed that there will be times when the conditions in higher education enhance or decrease academicians' feelings of affinity for their post-secondary institutions.

\section{Sample and Method}

In 1976, the Center for Research on Learning and Teaching (CRLT) at the University of Michigan conducted extensive interviews with 65 male faculty members who were appointed to the College of Literature, Science, and the 
Arts as assistant professors in either 1960,1965 , or 1970 . The appointment cohorts were established in order to include people who were considered for promotion and/or tenure during periods of institutional expansion and retrenchment (Ericksen and Moore, 1978).

During the interviews, respondents were asked to reflect on both their current and past experiences and to comment on various aspects of their careers at the university. Among the topics selected for the present study were: changes in their distribution of effort across teaching, research, and service; criteria applied to their own promotion, tenure, and merit decisions, the amount of departmental consensus regarding these criteria, changes in the emphasis of criteria since their appointment, and the ideal set of standards they would apply; and rate of promotion within the university. Each respondent submitted an updated copy of his curriculum vita. The vitae were used to determine the time spent in different academic ranks (rate of promotion) and the level of research, service, and teaching activity during each of four periods (pre-1960, 1961-65, 1966-70, 1971-75). The periods corresponded generally to the time each cohort spent in graduate school, as assistant professors working toward tenure, and as associate professors seeking promotion to the rank of professor.

The reader needs to keep in mind that those interviewed were academic "winners." With the exception of a few assistant professors in the 1970 cohort who were still at that rank when interviewed in 1976, the sample is composed of those who were successful in achieving tenure and advancement in rank.

\section{ANALYSES AND RESULTS}

Data were analyzed to test several generalizations about the sources of variance in faculty members' perceptions and behavior. The researchers combined the data from the interviews and vitae and identified across and within groups differences for the period 1961-1975. Two-way frequency tables, correlations, and analysis of variance procedures were used to examine the nature and extent of the differences.

The major subgroups used in the analyses were appointment cohort, generation, and discipline. The three appointment cohorts were taken to be all persons appointed as assistant professors in 1960, 1965, or 1970; the maximum usable $\mathrm{Ns}$ for the respective cohorts were 14, 28, and 15. Age groups were defined by decade of birth $-1921-30,1931-40$, and 1941-50. The discipline groups were humanities, social sciences, natural sciences-math, and other. Table 1 indicates departments subsumed within the groups and distribution of respondents across groups.

Scholarly productivity was a direct count from faculty vitae of all distinct, original conference papers, articles, books, and reviews. No attempt was 
TABLE 1. Departments within Disciplinary Groups

\begin{tabular}{|c|c|c|c|}
\hline $\begin{array}{l}\text { Humanities } \\
\qquad(N=20)\end{array}$ & $\begin{array}{l}\text { Social Sciences } \\
\qquad(N=22)\end{array}$ & $\begin{array}{l}\text { Natural Sciences } \\
\quad(N=18)\end{array}$ & $\begin{array}{l}\text { Other }^{a} \\
(N=5)\end{array}$ \\
\hline Classical Studies & Anthropology & Astronomy & Computer Sciences \\
\hline English & Economics & Botany & Journalism \\
\hline German & Geography & Chemistry & Speech \\
\hline History of Art & History & Geology & \\
\hline Near Eastern Studies & Political Science & Math & \\
\hline Philosophy & Psychology & Physics & \\
\hline Romance Languages & Sociology & Zoology & \\
\hline
\end{tabular}

${ }^{a}$ Data on this group are not reported in the findings.

made to assign relative weights to publications on the basis of either nature or quality.

\section{RESULTS}

For discussion purposes, the results are divided into three categories: those that relate to between-group differences in scholarly productivity, perceptions of promotion criteria, and rate of professional advancement. Each finding is interpreted from an aging, cohort, and historical perspective and inferences are drawn about which explanatory scheme best accounts for the outcome.

\section{Scholarly Productivity}

Total number of publications were counted for the three five-year periods, 1961-65, 1966-70, and 1971-75. There were no significant differences across the disciplinary areas (humanities, natural sciences, and social sciences) for any of the three time spans; hence, no controls for this variable were introduced in subsequent analyses.

When the data were tested by age groups, some shifts with age appeared, but there were no statistically (anova) significant outcomes. In addition, there were no linear trends indicating either an increase or a decrease with age. In short, publication rate was essentially constant over time.

The sample was divided into subgroups by year of promotion to associate professor and to full professor, and publication rates were examined in relation to these marker events. The data indicated that no significant change took place after advance to either academic rank. There did appear to be a slight build-up just prior to promotion, then a momentary decline, and then a resumption of modal behavior. For one of the promotion subgroups, 
productivity stayed constant, in another it fell, and in two the rate rose. At the promotion to full professor, one group's productivity fell after achieving that rank, whereas the other three groups displayed an increase in publications. (This last outcome is somewhat confounded with an overlap of the pre- and post-promotion time.)

Some differences appear, however, when successive five-year productivity periods are cross-tabulated with appointment cohorts (those appointed in 1960, 1965, or 1970). As can be seen in Table 2, the 1960 cohort is decreasing its output with the passage of time whereas the 1965 cohort has increased its productivity. Most striking is the 1970 cohort. They have an appreciably higher publication rate before being hired as assistant professors than either of the other two cohorts. Furthermore, the average publication rate during the first five years at the university was not only higher for the 1970 cohort, but the within-group variation was also smaller.

The differences that appear across faculty appointment groups suggest that they varied with respect to involvement in research during graduate studies - a cohort effect they may carry with them throughout their careers. On the other hand, the lack of correlation between age and productivity does not support a developmental interpretation of the trend. A historical explanation is also less plausible because during the same time period (197175), the publication rates were higher for the 1965 and 1970 cohorts, but lower for the 1960 cohort. Had the overall trend been an increase, it may have been indicative of a period effect - an increase in the institutional pressure to publish. In all, then, the cohort framework is the most fruitful explanatory schema for this phenomenon.

\section{Promotion Criteria and Ideals}

Table 3 displays the relative weights each of the three cohorts believe were given to research, teaching, and service at the time they were promoted to associate professor and received tenure. The interview respondents divided the three roles into fractions of a whole, and the weights are expressed as percents - e.g., as a group the 1960 cohort said that research counted 43.1/100 of the decision, teaching 33.5/100, and service 23.1/100.

Analysis of variance produced statistically significant $F$ values for both the research and the service roles. The differences are in accord with the believed truths, namely, an increasing weight being given to publishing scholarly works and a decreasing importance being given to service. (The significant $F$ values disappear when control for discipline is introduced.) ${ }^{2}$

When one asks these faculty what the ideal weighting should be for promotion to associate and to full professor, quite a different picture emerges. As can be seen in Table 4, the statistically significant differences have disap- 


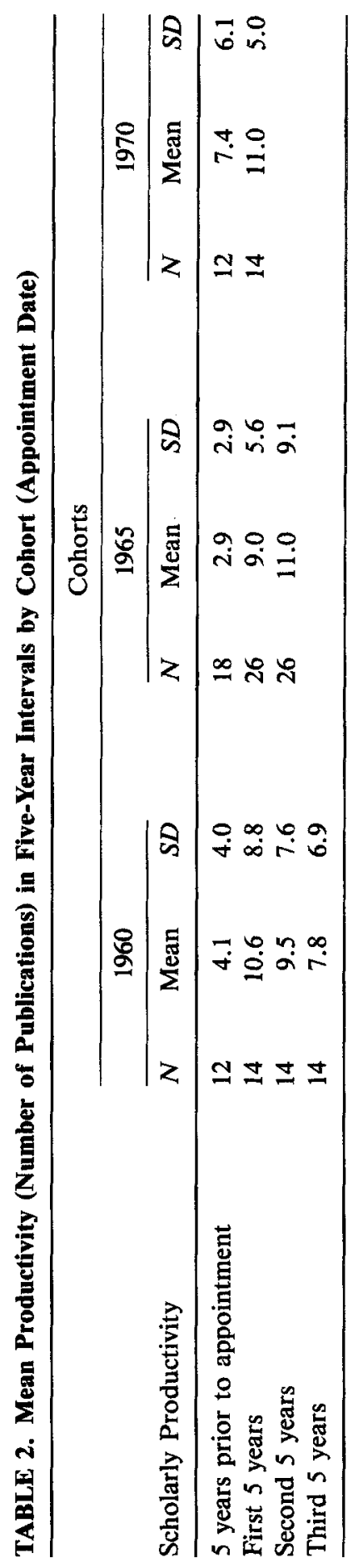




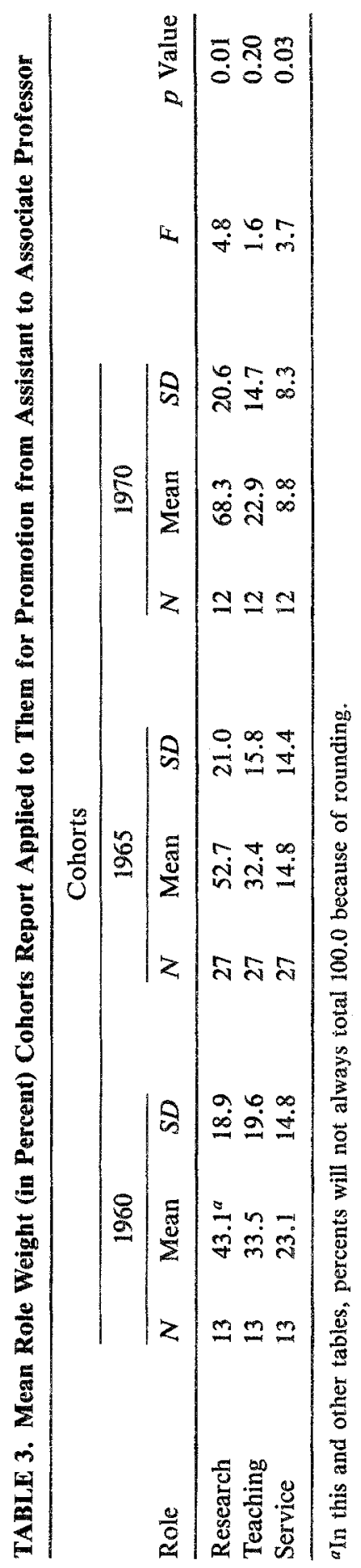




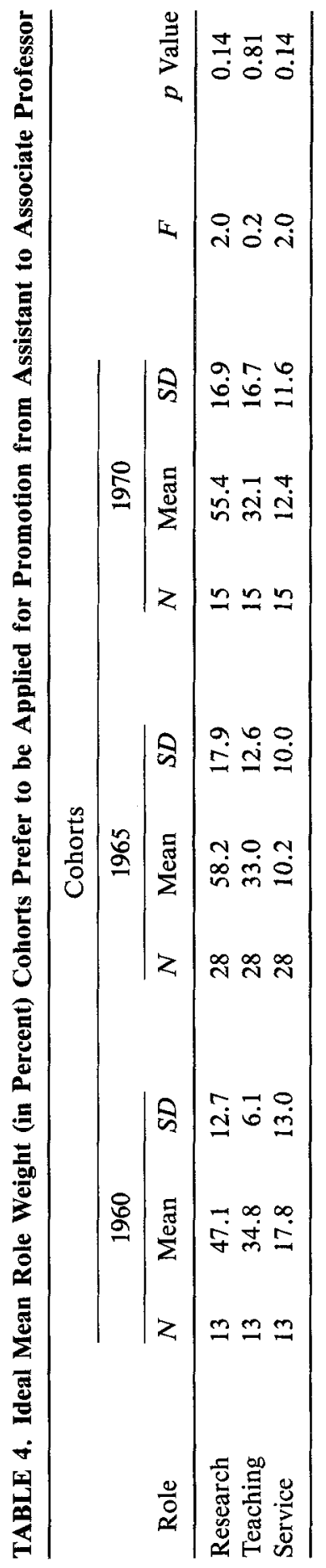


peared. While the most recent cohort assigns a higher weight to research than does the oldest, ideally they believe that it should be $13 \%$ less than they think was applied in their own tenure decisions. In contrast, the oldest cohort's ideal distribution of weight gives more emphasis to research than they believe was the case when they were reviewed. Similar adjustments, but in the opposite direction, have been given to the service role.

Historical and cohort interpretations of these phenomena seem appropriate. Although each successive cohort believed that different values were actually assigned to their research and service, within and across cohorts there was a sense that research was being given more emphasis in all promotion decisions. Over time, then, the trend was in the same direction, and one can speculate that it was due to shifts occurring in institutional priorities (e.g., changes in college administration, changes in national ratings of certain departments). Cohort explanations for the different perceptions are also tenable. It could be that the 1960 and 1970 cohorts' higher productivity rates and beliefs that greater weight was assigned to research in tenure decisions is due to the role that the former professors played in selecting and promoting the latter group. The homogeneity with respect to ideal weights might indicate that the respondents, with the passage of time and selective retention of professors, developed a similar outlook.

Faculty members were asked the degree of consensus that they believed existed within their departments with respect to the criteria applied in promotion decisions. There were no significant differences by either age or cohort. On both analyses, however, there was a regular progression from the older to the younger (age and cohort) with the oldest believing more strongly that there was departmental consensus. Moreover, there was a regular progression in the magnitude of the standard deviation from smaller to larger over time. That is, not only was there a stronger expression of agreement in the oldest group; there also was less variation in that belief. Again this could be a cohort effect. Those who do not share the values of the dominant group may have been separated out, voluntarily or otherwise.

When the data on how faculty distributed their time over the three roles were correlated with the weight that they believe was given to each activity for promotion, there were significant correlations for the passage from assistant to associate professor but not from associate to full professor (except in the case of service where everyone thought it did not count and few seemed to give any effort to it). (See Table 5.)

Two observations are made regarding these data. First, contrary to what is frequently stated by assistant professors about not knowing what are the criteria for success, the people who were awarded tenure apparently did understand and acted accordingly. We do not know about the noncontinuing, a fact that must be kept in mind with all of these data and that is returned 


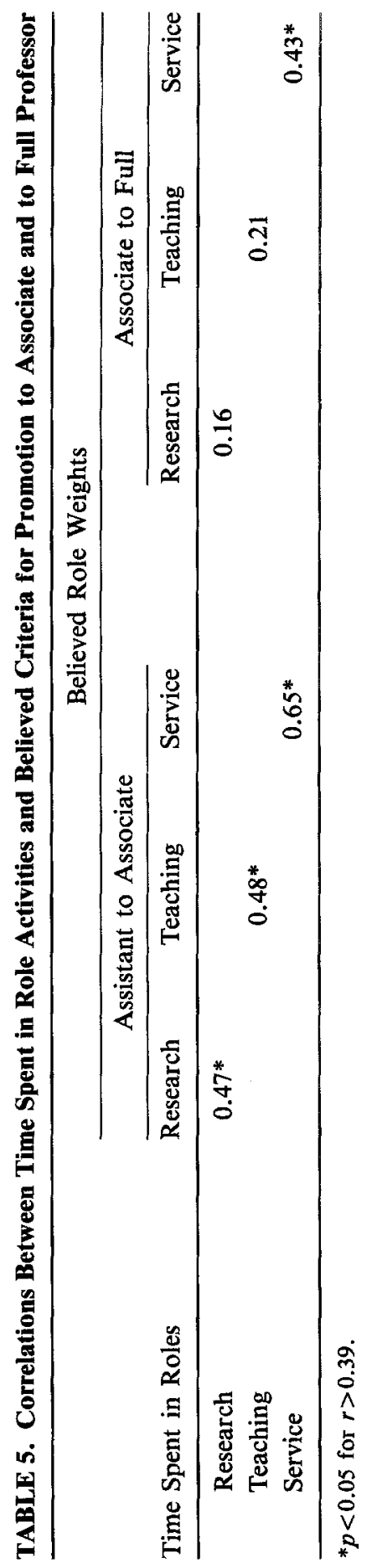


to in the discussion section. Second, after they were tenured, the faculty members seemed to act in ways that were inconsistent with what they believed would guarantee the final promotion. Given extant knowledge, this withincohort variance is best explained as an aging effect. It is reasonable to think that associate professors, now freed from strong external pressures, are searching for a preferred balance among their roles. However, as more information is gathered regarding staffing patterns and priorities within departments, some alternative demographic explanations for this phenomenon may emerge.

When correlations were run between how respondents distributed their effort and how they assigned ideal weights to promotion criteria, there were no significant correlations on either teaching or research. Whether such discrepancies were a source of stress for these academicians is not known. However, this finding fits with previous studies, which found that professors might identify more with their roles as teachers but do not necessarily devote more time to this activity. Together, the results raise doubts about the usefulness of questions about ideals.

Last, when the "believed to be" criteria for promotion to both the associate and full professor levels were examined across discipline groups, the significant differences displayed above (Table 3 ) with respect to research and service disappear (see Tables 6 and 7). Only in the case of teaching and promotion to full professor does an $F$ approach statistical significance, and that may come about largely because of the high value humanities faculty have traditionally given to this role. When asked to explain shifts in the promotions/tenure criteria, respondents often noted that decisions were becoming centralized. Whereas in the past departmental recommendations were endorsed rather routinely at the college level, in 1976 the respondents noted that these recommendations were sometimes not accepted. At the time of this study, the college administrators were from the social and natural sciences, and the folklore was that models used in these disciplines, which stressed publication far above teaching, were being applied in all tenure decisions. The evidence is circumstantial, but it does pique one's interest in the possible historical/cohort explanation for this phenomenon.

\section{Promotion Rate}

The frequently heard claims that it is more difficult to acquire tenure and/or secure a promotion today than it was yesterday and that those who do will stay longer in each rank is not supported by these data. As can be seen in Table 8, assistant professors have spent four years in rank after appointment, and that is true for each successive cohort. Furthermore, the within-cohort variation is low and essentially identical. Those people who achieve tenure are not spending the full six years as assistant professors, 


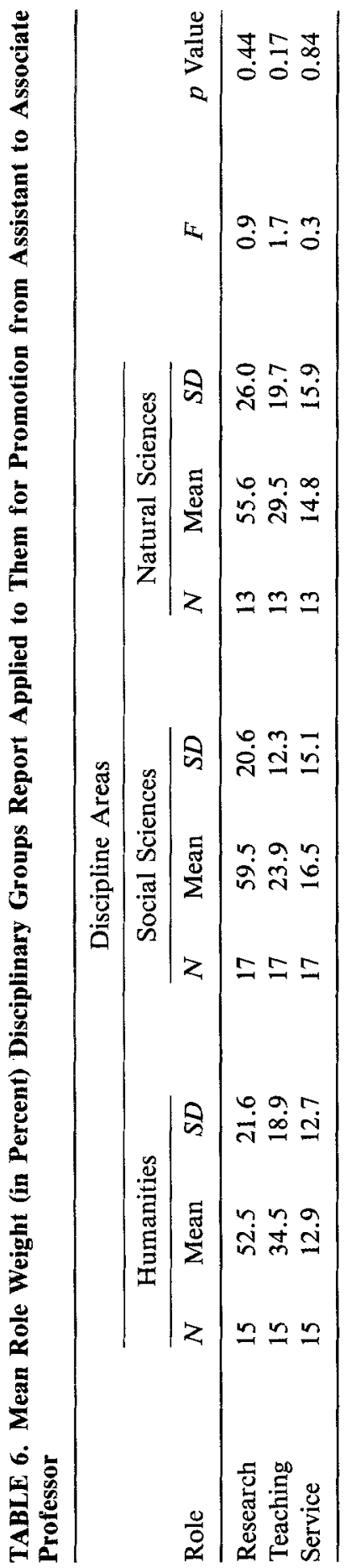




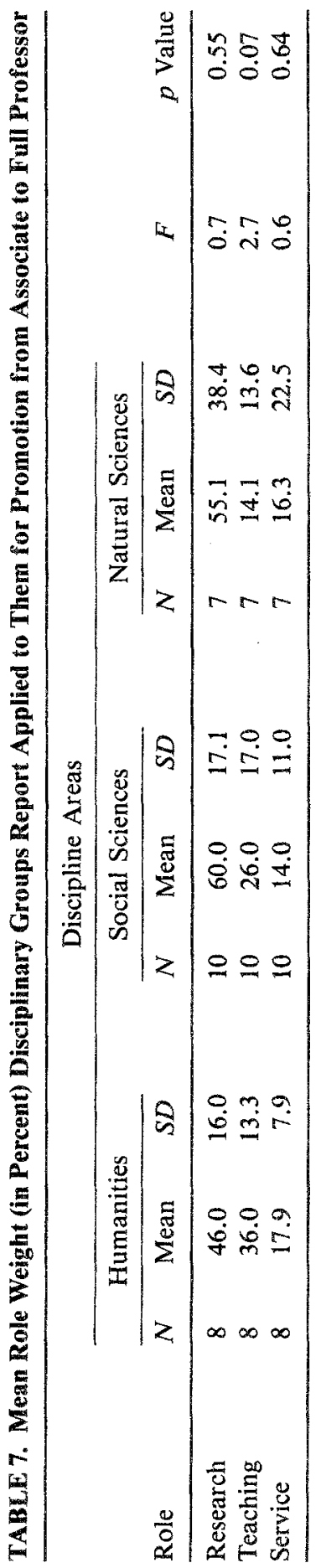




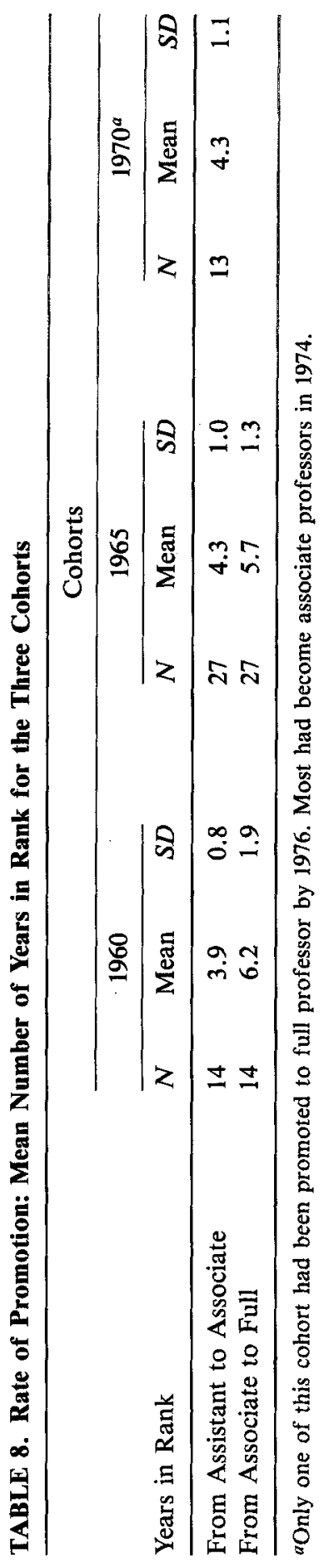


regardless of their area of discipline. They are being advanced ahead of "schedule." The same holds for the promotion to full professor, although at this career point there is no AAUP guideline for how long one can be expected to be in a grade before promotion.

Why there is constancy across cohorts is not known, and the reason for four years may differ with historical events. For example, the less-than-sixyears to tenure in the 1960s may have resulted from the faculty shortage that then existed. That is, the university may have given early promotion in order not to lose able people whom they had recruited. By the 1970 s and the end of expansion, the university may not have been as worried about loss by raiding. However, they have hired people who are more productive (both prehire and immediately after appointment) and may be rewarding them with early promotion. Or it may be that the university norm has been and continues to be four years, despite historical events that could affect decisions. The data do not allow one to select from among these alternative explanations.

\section{DISCUSSION}

The major limitations of the study are readily apparent and are mentioned but not elaborated upon. The sample size is small and, hence, restricts the level of analysis. (Too frequently controls could not be introduced.) The smallness of the sample also requires aggregations that are undesired. (Not all of the departments in a disciplinary area are alike in terms of norms or values.) Another sample limitation results from having only three cohorts. If there were groups on either side-say, 1950 and 1975-one would be in a much better position to sort out the relative strengths and weaknesses of the three explanatory schemes. ${ }^{3}$

As for the three explanatory schemes, each was utilized on at least one occasion to account for the data. However, the maturation, or aging, explanation was borne out only once. Furthermore, in several instances, the outcomes were contrary to the expectations of the aging perspective. The demographic/cohort explanation was the most effective in accounting for the data, especially when historical events were also taken into account. With respect to certain aspects of faculty careers, then, this latter combination seems to be the most powerful.

Many personnel practices, especially those carried out under the auspices of faculty development, are based on inferences about the age-relatedness of certain changes in career interests and motivations. The evidence from this exploratory study does not support the general premise that sequential and unidirectional shifts occur as a result of an ongoing life review process. Rather, the findings clearly point to the need for more sophisticated analyses 
of cause-effect relationships between individual and institutional variables and career patterns.

Several areas for further research are suggested by the study results. Two are particularly crucial at this time. First, the findings call attention to the importance of early career socialization experiences; this is not a new conclusion, but one that ought to be underscored. Mentor role models and opportunities for enhancement of teaching and scholarship appear to influence the values and activities of graduate students, as well as their chances of obtaining an initial appointment. Furthermore, the behavior patterns seem to persist, and administrators should anticipate that faculty age-group norms may be altered as a result of cohort flow. Faculty development researchers must begin to distinguish resistance to change that accrues over time as the result of human aging processes from resistance to change that manifests itself when proposals run counter to professors' longstanding core values.

Second, the data raise some interesting questions about the role of junior professors in bringing about changes within postsecondary institutions. Based on the study findings, one could conclude that the dominant cohort within a department or college will hire new professors who fit into existing structures and who will bring about predetermined changes. Junior faculty members who achieved tenure were aware of the decision criteria, suggesting they experienced pressure to conform. The data lead one to question whether maintaining faculty vitality means stimulating senior professors' interests in new areas of research and teaching or carrying on the legacy of the dominant group. The present data set does not allow the researchers to draw conclusions about the extent to which those who were not granted tenure tried to pursue individual interests or bring about changes in the system. Future investigators should, however, give priority to this question.

Collectively, these data describe the forces that pull and tug on the careers of academicians. No one theoretical model can account for the diversity of professional interests and activities that characterize a college faculty or a segment of it. Researchers who give careful attention to the alternative interpretations for faculty behaviors will better illuminate critical issues than will the many who quickly advance a singular explanation.

Acknowledgment. We are indebted to Terry Ging for his assistance in coding and statistically treating the data.

\section{NOTES}

1. This assertion has been tested and borne out by Clark and Corcoran (1982), who recently examined activities during graduate school and the initial stages in faculty careers. 
2. The weights that faculty report are used for promotion to full professor are essentially the same. They are not displayed here, however, in part because only one of the 1970 cohort had received that promotion by 1976 , the initial data collection time.

3. We are happy to report that this last deficiency is about to be removed. A small grant from TIAA/CREF will allow us to add these cohorts to our study and to reinterview members of this original sample.

\section{REFERENCES}

Baldwin, R., and Blackburn, R. (1981). The academic career as a developmental process: Implications for higher education. Journal of Higher Education 52: $598-$ 614.

Bayer, A. E., and Dutton, J. E. (1977). Career age and research/professional activities of academic scientists: Tests of alternative nonlinear models and some implications for higher education faculty policies. Journal of Higher Education 48: 259-282.

Blackburn, R., Behymer, C., and Hall, D. (1978). Corrleates of faculty publications. Sociology of Education 51: 132-141.

Braskamp, L., Fowler, D., and Ory, J. (1982). Faculty development and achievement: A faculty's view. Paper presented at the annual meeting of the American Educational Research Association, New York, April.

Cartter, A. M. (1976). Ph.D.s and the Academic Labor Market. New York: McGrawHill.

Clark, S. M., and Corcoran, M. (1982). Professional socialization and faculty career vitality. Paper presented at the annual meeting of the American Educational Research Association, Montreal, Canada, April.

Cutler, N., and Bengtson, V. (1974). Age and political alienation: Maturation, generation and period effects. The Annals of the American Academy of Political and Social Science 415: 160-175.

Ericksen, S., and Moore, W. (1978). The dimensions of merit. Memo to the Faculty 61, Center for Research on Learning and Teaching, University of Michigan.

Fulton, O., and Trow, M. (1974). Research activity in American higher education. Sociology of Education 47: 29-73.

Hodgkinson, H. L. (1974). Adult development: Implications for faculty and administrators. Educational Record, 263-274.

Kimmel, D. C. (1974). Adulthood and Aging. New York: Wiley.

Klapper, H. L. (1969). The young college faculty member - A new breed? Sociology of Education 42: 38-49.

Light, D. W., Jr. (1974). The structure of the academic professions. Sociology of Education 47: 2-28.

Long, J. S. (1978). Productivity and academic position in the scientific career. American Sociological Review 43: 889-908.

McCain, B. E., O'Reilly, C., and Pfeffer, J. (1982). The effects of departmental demography on turnover: The case of a university. Mimeographed paper, University of lowa, June. 
Parsons, T., and Platt, G. M. (1973). The American University. Cambridge: Harvard University Press.

Pelz, D. C., and Andrews, F. M. (1976). Scientists in Organizations (rev. ed.). New York: Wiley.

Pfeffer, J., Leong, A., and Strehl, K. (1976). Publication and prestige mobility of university departments in three scientific disciplines. Sociology of Education 49: 212-218.

Pfeffer, J. (1983). Organizational demography. In Cummings, L., and Staw, B. (Eds.), Research in Organizational Behavior, Vol. 5. Greenwich, CT: JAI Press.

Sanford, N. (1971). Academic culture and the teacher's development. Soundings, 357-371.

Trow, M. (1977). Departments as contexts for teaching and learning. In McHenry, D., et al. (Eds.), Academic Departments. San Francisco: Jossey-Bass, 12-33.

Received October 1, 1984 